\title{
SISTEM DETEKSI EMOSI MENGGUNAKAN SINYAL EEG EMOCLASS
}

\section{Emotion Detection System Using EEG Emoclass Signal}

\author{
Ngarap Imanuel Manik, manik@binus.ac.id ${ }^{1)}$, Antonius Ivan, aivan@yahoo.com ${ }^{2)}$ \\ ${ }^{12)}$ Mathematics Departement, School of Computer Science, Bina Nusantara University
}

\begin{abstract}
An emotional detection system has been developed using Emoclass EEG signals with the help of a new computer program. Therefore the results of this development are an important step in progress in learning the classification of emotional detection because it can be obtained more quickly. This study uses a support vector machine approach with a statistical analysis model that can be used to classify emotions into the Russell Emotion Model. Emotions included are Amused, Fear, Calm, Sad, and Neutral. Evaluation results the accuracy of detection of emotion through a supervised learning approach to provide accuracy of 50\%-100\% overall. Detection of emotion arousal levels (intensity) of high emotions such as fear, amused can provide results accurate, revolves around emotions in the 90\%. This is due to the ease to classify EEG signals data if emotions has an mean and standard deviation are quite high.
\end{abstract}

Keywords: Emotion detection, EEG, Support vector machine

\begin{abstract}
ABSTRAK
Pengembangan sistem deteksi emosi menggunakan sinyal EEG Emoclass dengan bantuan program komputer masih baru, oleh sebab itu hasil pengembangan ini merupakan langkah penting dalam kemajuan pembelajaran klasifikasi deteksi emosi karena dapat diperoleh dengan lebih cepat. Penelitian ini menggunakan pendekatan support vector machine dengan model analisis statistika yang dapat digunakan untuk mengklasifikasikan emosi ke dalam Model Emosi Russell. Emosi yang termasuk adalah Amused, Fear, Calm, Sad, dan Neutral. Hasil evaluasi keakuratan deteksi emosi melalui pendekatan supervised learning memberikan akurasi 50\%-100\% secara keseluruhan. Pendeteksian emosi dengan tingkat arousal (intensitas) emosi tinggi seperti fear, amused dapat memberikan hasil emosi yang akurat, berkisar di angka 90\%. Hal ini disebabkan kemudahan untuk mengklasifikasikan emosi jika data sinyal EEG memiliki rata-rata (mean) maupun simpangan baku (standar deviasi) yang cukup tinggi.
\end{abstract}

Kata Kunci: Deteksi emosi, EEG, Support vector machine

\section{PENDAHULUAN}

Emosi adalah hal yang sudah menjadi salah satu bagian terpenting bagi kehidupan seorang manusia. Dengan emosi yang sehat, kita dapat melakukan segala aktivitas maupun bekerja.[4] Emosi memainkan peran penting dalam cara kita memilih dan mengkonsumsi multimedia. Perkembangan teknologi multimedia dan intelejensia semu akhir-akhir ini, memberikan kesempatan kepada komputer untuk melakukan sendiri suatu komputasi afektif.[2]
Umumnya psikolog menyajikan emosi dan perasaan ke dalam ruang dimensi 2 atau 3D. Bentuk ruang yang paling terkenal adalah Valence-Arousal-Dominance (Valensi - Intensitas emosi - Pembagian dominasi). Spektral daya dari sinyal Elektro Ensefalografi (EEG) yang digunakan sebagai fitur untuk mendeteksi tingkat valensi setiap frame. Dalam hal itu pembacaan database afektif sangatlah penting untuk membuat komputer dapat mengetahui emosi manusia. Dalam tulisan 
ini penulis memaparkan tahap-tahap dalam proses pengembangan aplikasi deteksi emosi menggunakan sinyal Elektro Ensefalografi (EEG).[5]

Media-media yang digunakan oleh penulis untuk menstimulasi munculnya emosi adalah short video. Konten multimedia yang salah satunya adalah short video, dibuat untuk mendorong timbulnya emosi. Oleh Karena itu dalam tulisan ini, penulis fokus ke deteksi emosi secara kontinu terhadap respon pengguna neuroheadset (EEG) terhadap short video tersebut.

Dalam penelitian ini digunakan model analisis statistika Pearson-Correlation Statistic. Kedua hal tersebut dapat dimanfaatkan untuk mengukur ketergantungan hubungan linear dari 2 variabel berbeda.[7]. Terdapat 2 langkah untuk menghitung Pearson-correlation, salah satu diantaranya yaitu mencari nilai covariance dari 2 dan membagi hasil covariance dengan perkalian dari masingmasing standar deviasinya.[3]

Rumus (1) merupakan rumus untuk menghitung koefisien Pearson-correlation serta support vector machine yang dapat digunakan untuk mengklasifikasikan emosi ke dalam Model Emosi Russell. Emosi yang termasuk adalah Amused, Fear, Calm, Sad, dan Neutral.[1]

$$
\rho(x, y)=\frac{\operatorname{cov}(x, y)}{\sigma_{x} \sigma_{y}} .
$$

Performa model yang paling baik didapatkan saat data disajikan. Dengan model ini akan membantu komputer mendeteksi respon afektif spontan dan halus dari manusia penggunanya. Hal tersebut dapat dicapai dengan pembuatan aplikasi deteksi emosi dengan memanfaatkan data yang tersedia. Aplikasi ini dibuat menggunakan bahasa Python. [7]

\section{METODE PENELITIAN}

Dalam peneltian ini tahapan yang dilakukan adalah sebagai berikut: Pengumpulan Data/informasi; mengumpulkan teori- teori dan memperhatikan penelitian sebelumnya yang berhubungan dengan pengembangan aplikasi ini baik dari buku,artikel,dan jurnal ilmiah. Kemudian membuat kuesioner sesuai kebutuhan di atas sebagai alat pengumpul data yang akan diolah serta mempelajari sistem aplikasi sejenis yang telah dikembangkan peneliti lain yang memiliki kesamaan dengan aplikasi peneliti untuk mendapatkan informasi dalam pengembangan algoritma

Metode yang digunakan dalam analisis data dalam penelitian ini adalah menggunakan Emotiv untuk perhitungan bagaimana sinyal EEG dapat diolah dan di transformasi menjadi frekuensi gelombang serta memanfaatkan bahasa pemrograman Python untuk proses analisis data tersebut.

Proses pengolahan data yang dilakukan dengan bantuan program Python yang mana dalam tahapan perancangan program ini mengikuti aturan yang sudah ada yaitu perancangan sistem dengan Unified Modeling Language (UML), perancangan Diagram alir, perancangan aplikasi dengan menggunakan metode Waterfall [6]

Secara keseluruhan pengembangan sistem ini diperagakan pada gambar 1 .

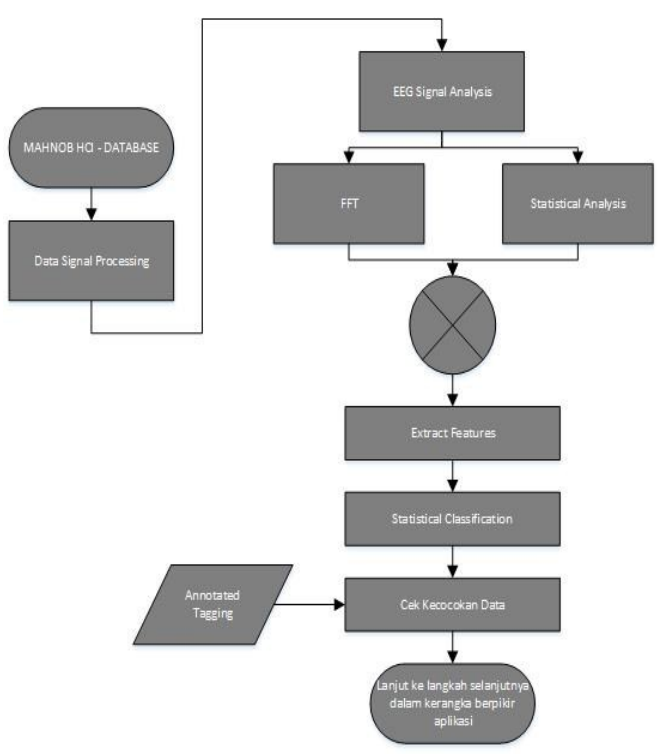

Gambar 1. Flow Chart System 


\section{HASIL DAN PEMBAHASAN}

\section{Evaluasi EmoClass}

Evaluasi objektif dilakukan dengan menggunakan 2 skenario evaluasi. Skenario pertama adalah membandingkan akurasi yang didapatkan dengan menggunakan algoritma classifier. Data yang dibandingkan pada penelitian ini adalah Expected Emotion dan Output yang dihasilkan.

Kecocokan data dicari dari hasil emosi akhir yang diinginkan dengan hasil data output dari sistem. Sistem memberikan hasil emosi kurang lebih 3 hasil emosi setiap detiknya. Sistem merekam hasil emosi selama Video berlangsung. Lalu menghitung persentase emosi yang dominan dengan rumus (2)[7]

$$
\text { Persentase }=\frac{n}{N} \times 100 \%
$$

\section{Keterangan:}

$\mathrm{n}=$ Jumlah data dari emosi yang dominan selama video berlangsung $\mathrm{N}=$ Jumlah data dari semua emosi selama video berlangsung

Tabel 1 sampai Tabel 10 menghadirkan hasil persentase dari tiap percobaan sebanyak 10 percobaan. Dari tabel 1. dapat dilihat bahwa pada percobaan 1 akurasi yang diperoleh sebesar $67,7 \%$. Dari tabel 2 dapat dilihat bahwa pada percobaan 2 akurasi yang diperoleh sebesar $100 \%$.

Tabel 1. Data Hasil Percobaan 1

\begin{tabular}{|r|l|l|c|c|}
\hline ID & Video & $\begin{array}{l}\text { Expected } \\
\text { Emotion }\end{array}$ & Output & \% \\
\hline 1 & $\begin{array}{l}\text { Gang's of } \\
\text { New York }\end{array}$ & Sadness & Fear & $64 \%$ \\
\hline 2 & $\begin{array}{l}\text { Mr. Bean's } \\
\text { Holiday }\end{array}$ & Amused & Amused & $63 \%$ \\
\hline 3 & The Shining & Fear & Fear & $60 \%$ \\
\hline
\end{tabular}

Tabel 2. Data Hasil Percobaan 2

\begin{tabular}{|r|l|l|l|c|}
\hline ID & Video & $\begin{array}{l}\text { Expected } \\
\text { Emotion }\end{array}$ & Output & $\%$ \\
\hline 1 & $\begin{array}{l}\text { Gang's of } \\
\text { New York }\end{array}$ & Sadness & Sadness & $54 \%$ \\
\hline 2 & $\begin{array}{l}\text { Mr. Bean's } \\
\text { Holiday }\end{array}$ & Amused & Amused & $53 \%$ \\
\hline 3 & The Shining & Fear & Fear & $51 \%$ \\
\hline
\end{tabular}

Tabel 3.Data Hasil Percobaan 3

\begin{tabular}{|r|l|l|l|c|}
\hline \multicolumn{1}{|l|}{ ID } & Video & $\begin{array}{l}\text { Expected } \\
\text { Emotion }\end{array}$ & Output & $\%$ \\
\hline 1 & $\begin{array}{l}\text { Gang's of } \\
\text { New York }\end{array}$ & Sadness & Sadness & $53 \%$ \\
\hline 2 & $\begin{array}{l}\text { Mr.Bean's } \\
\text { Holiday }\end{array}$ & Amused & Amused & $52 \%$ \\
\hline 3 & $\begin{array}{l}\text { The } \\
\text { Shining }\end{array}$ & Fear & Fear & $52 \%$ \\
\hline
\end{tabular}

Tabel 3 menginformasikan bahwa pada percobaan 3 akurasi yang diperoleh sebesar $100 \%$. Dari tabel 4 dapat dilihat bahwa pada percobaan 4 akurasi yang diperoleh sebesar 100\%. Dari tabel 5 dapat dilihat bahwa pada percobaan 5 akurasi yang diperoleh sebesar 67,7\%.. Tabel 6 menunjukkan pada percobaan 6 akurasi yang diperoleh sebesar $67,7 \%$. Dari tabel 7 dapat dilihat bahwa pada percobaan 7 akurasi yang diperoleh sebesar $100 \%$.

Tabel 4. Data Hasil Percobaan 4

\begin{tabular}{|r|l|l|l|c|}
\hline ID & Video & $\begin{array}{l}\text { Expected } \\
\text { Emotion }\end{array}$ & Output & $\%$ \\
\hline 1 & $\begin{array}{l}\text { Gang's of } \\
\text { New York }\end{array}$ & Sadness & Sadness & $52 \%$ \\
\hline 2 & $\begin{array}{l}\text { Mr. Bean's } \\
\text { Holiday }\end{array}$ & Amused & Amused & $53 \%$ \\
\hline 3 & The Shining & Fear & Fear & $60 \%$ \\
\hline
\end{tabular}

Tabel 5. Data Hasil Percobaan 5

\begin{tabular}{|r|l|l|l|c|}
\hline \multicolumn{1}{|l|}{ ID } & Video & $\begin{array}{l}\text { Expected } \\
\text { Emotion }\end{array}$ & Output & $\%$ \\
\hline 1 & $\begin{array}{l}\text { Gang's of } \\
\text { New York }\end{array}$ & Sadness & Fear & $54 \%$ \\
\hline 2 & $\begin{array}{l}\text { Mr.Bean's } \\
\text { Holiday }\end{array}$ & Amused & Amused & $88 \%$ \\
\hline 3 & The Shining & Fear & Fear & $54 \%$ \\
\hline
\end{tabular}

Tabel 6. Data Hasil Percobaan 6

\begin{tabular}{|r|l|l|l|c|}
\hline ID & Video & $\begin{array}{l}\text { Expected } \\
\text { Emotion }\end{array}$ & Output & $\%$ \\
\hline 1 & $\begin{array}{l}\text { Gang's of } \\
\text { New York }\end{array}$ & Sadness & Sadness & $53 \%$ \\
\hline 2 & $\begin{array}{l}\text { Mr.Bean's } \\
\text { Holiday }\end{array}$ & Amused & Fear & $51 \%$ \\
\hline 3 & The Shining & Fear & Fear & $51 \%$ \\
\hline
\end{tabular}

Percobaan 8 yang diperagakan pada tabel 8 Dari tabel di atas. Menunjukkan bahwa pada percobaan 8 akurasi yang diperoleh sebesar $100 \%$. Dari tabel 9 dapat dilihat bahwa pada percobaan 9 akurasi yang diperoleh sebesar $67,7 \%$. Dari tabel 10 dapat dilihat bahwa pada percobaan 10 akurasi yang diperoleh sebesar $100 \%$. 
Tabel 7. Data Hasil Percobaan 7

\begin{tabular}{|r|l|l|l|c|}
\hline ID & Video & $\begin{array}{l}\text { Expected } \\
\text { Emotion }\end{array}$ & Output & $\%$ \\
\hline 1 & $\begin{array}{l}\text { Gang's of } \\
\text { New York }\end{array}$ & Sadness & Sadness & $56 \%$ \\
\hline 2 & $\begin{array}{l}\text { Mr.Bean's } \\
\text { Holiday }\end{array}$ & Amused & Amused & $56 \%$ \\
\hline 3 & The Shining & Fear & Fear & $60 \%$ \\
\hline
\end{tabular}

Tabel 8. Data Hasil Percobaan 8

\begin{tabular}{|r|l|l|l|c|}
\hline ID & Video & $\begin{array}{l}\text { Expected } \\
\text { Emotion }\end{array}$ & Output & $\%$ \\
\hline 1 & $\begin{array}{l}\text { Gang's of } \\
\text { New York }\end{array}$ & Sadness & Sadness & $58 \%$ \\
\hline 2 & $\begin{array}{l}\text { Mr.Bean's } \\
\text { Holiday }\end{array}$ & Amused & Amused & $53 \%$ \\
\hline 3 & The Shining & Fear & Fear & $60 \%$ \\
\hline
\end{tabular}

Tabel 9. Data Hasil Percobaan 9

\begin{tabular}{|r|l|l|l|l|}
\hline ID & Video & $\begin{array}{l}\text { Expected } \\
\text { Emotion }\end{array}$ & Output & $\%$ \\
\hline 1 & $\begin{array}{l}\text { Gang's of } \\
\text { New York }\end{array}$ & Sadness & Fear & $54 \%$ \\
\hline 2 & $\begin{array}{l}\text { Mr.Bean's } \\
\text { Holiday }\end{array}$ & Amused & Amused & $71 \%$ \\
\hline 3 & The Shining & Fear & Fear & $54 \%$ \\
\hline
\end{tabular}

Tabel 10. Data Hasil Percobaan 10

\begin{tabular}{|c|l|l|l|l|}
\hline ID & \multicolumn{1}{|c|}{ Video } & $\begin{array}{c}\text { Expected } \\
\text { Emotion }\end{array}$ & Output & Persentase \\
\hline 1 & $\begin{array}{l}\text { Gang's of } \\
\text { New York }\end{array}$ & Sadness & Sadness & $51 \%$ \\
\hline 2 & $\begin{array}{l}\text { Mr.Bean's } \\
\text { Holiday }\end{array}$ & Amused & Amused & $56 \%$ \\
\hline 3 & The Shining & Fear & Fear & $56 \%$ \\
\hline
\end{tabular}

Tabel 11. Data Lengkap Hasil Percobaan Emosi Neutral

\begin{tabular}{|c|l|l|c|}
\hline ID & \multicolumn{1}{|c|}{ Video } & \multicolumn{1}{|c|}{$\begin{array}{c}\text { Expected } \\
\text { Emotion }\end{array}$} & Output \\
\hline 1 & $\begin{array}{l}\text { (New York's Weather } \\
\text { Forecast) } \\
\text { (New York's Weather } \\
\text { Forecast) }\end{array}$ & Neutral & Amused \\
\hline 3 & $\begin{array}{l}\text { (New York's Weather } \\
\text { Forecast) }\end{array}$ & Neutral & Calm \\
\hline 4 & $\begin{array}{l}\text { (New York's Weather } \\
\text { Forecast) }\end{array}$ & Neutral & Amused \\
\hline 5 & $\begin{array}{l}\text { (New York's Weather } \\
\text { Forecast) }\end{array}$ & Neutral & Amused \\
\hline 6 & $\begin{array}{l}\text { (New York's Weather } \\
\text { Forecast) }\end{array}$ & Neutral & Calm \\
\hline 7 & $\begin{array}{l}\text { (New York's Weather } \\
\text { Forecast) }\end{array}$ & Neutral & Amused \\
\hline 8 & $\begin{array}{l}\text { (New York's Weather } \\
\text { Forecast) }\end{array}$ & Neutral & Amused \\
\hline 9 & $\begin{array}{l}\text { (New York's Weather } \\
\text { Forecast) }\end{array}$ & Neutral & Amused \\
\hline 10 & $\begin{array}{l}\text { (New York's Weather } \\
\text { Forecast) }\end{array}$ & Neutral & Amused \\
\hline & & korelasi & $0 \%$ \\
\hline
\end{tabular}

Tabel 12. Perbandingan Hasil oleh 10 Skenario
Maka hasil dari 10 percobaan untuk emosi Amused, Fear, Sadness adalah $87,108 \%$ akurasinya. Penulis juga melakukan percobaan dengan harapan emosi Neutral. Namun karena beberapa sebab, maka hasil yang didapat penulis kurang memuaskan (lihat pembahasan). Korelasi antara harapan emosi yang diinginkan dengan apa yang sistem deteksi. Ditunjukkan pada tabel 11

\begin{tabular}{|c|c|c|c|c|}
\hline $\begin{array}{l}\text { I } \\
\text { D }\end{array}$ & $\begin{array}{c}\text { Skenar } \\
\text { io }\end{array}$ & $\begin{array}{l}\text { Rata- } \\
\text { rata } \\
\text { Akur } \\
\text { asi }\end{array}$ & $\begin{array}{l}\text { Rata-rata } \\
\text { Tingkat } \\
\text { Kepercay } \\
\text { aan } \\
\text { Deteksi } \\
\text { Emosi }\end{array}$ & Deskripsi \\
\hline 1 & Fear & $100 \%$ & 0,558 & $\begin{array}{l}\text { Short } \\
\text { Video yang } \\
\text { diputar } \\
\text { adalah } \\
\text { cuplikan } \\
\text { dari "The } \\
\text { Shining" }\end{array}$ \\
\hline 2 & $\begin{array}{l}\text { Amuse } \\
\mathrm{d}\end{array}$ & $90 \%$ & 0,586 & $\begin{array}{l}\text { Short } \\
\text { Video yang } \\
\text { diputar } \\
\text { adalah } \\
\text { cuplikan } \\
\text { dari } \\
\text { "Mr.Bean' } \\
\text { s Holiday" }\end{array}$ \\
\hline 3 & $\begin{array}{l}\text { Sadnes } \\
\mathrm{s}\end{array}$ & $70 \%$ & 0,549 & $\begin{array}{l}\text { Short } \\
\text { Video yang } \\
\text { diputar } \\
\text { adalah } \\
\text { cuplikan } \\
\text { dari } \\
\text { "Gangs of } \\
\text { New York" }\end{array}$ \\
\hline 4 & Neutral & $0 \%$ & $0 \%$ & $\begin{array}{l}\text { Short } \\
\text { Video yang } \\
\text { diputar } \\
\text { adalah } \\
\text { cuplikan } \\
\text { dari } \\
\text { "AccuWeat } \\
\text { her New } \\
\text { York" }\end{array}$ \\
\hline
\end{tabular}

Tabel 12 memperagakan summary dari seluruh percobaan diperoleh bahwa pendeteksian emosi yang dilakukan dengan harapan emosi Fear dan Amused memberikan hasil yang paling baik dibanding percobaan lainnya karena 
intensitas emosi yang dikeluarkan tinggi, sehingga mudah untuk diklasifikasikan.

Pada pendeteksian emosi dengan harapan emosi Sadness memberikan hasil yang sedang. Hal ini disebabkan karena arousal(intensitas) dari harapan emosi tergolong rendah dan sulit di klasifikasikan.

\section{SIMPULAN}

\section{Simpulan}

Pendekatan supervised learning dengan menggunakan model support vector machine dapat diterapkan dalam sebuah aplikasi untuk sistem deteksi emosi. Hasil evaluasi keakuratan deteksi emosi melalui pendekatan supervised learning memberikan akurasi 50\%-100\% secara keseluruhan. Pendeteksian emosi dengan tingkat arousal (intensitas) emosi tinggi seperti fear, amused dapat memberikan hasil emosi yang akurat, berkisar di angka 90\%.. Hal ini disebabkan kemudahan untuk mengklasifikasikan emosi jika data sinyal EEG memiliki rata-rata (mean) maupun simpangan baku(standar deviasi) yang cukup tinggi. Beberapa emosi seharusnya cukup baik dikenali oleh "EmoClass" yaitu sad dan calm, namun dikarenakan keterbatasan short video beranotasi calm, maka penulis hanya dapat memastikan keakurat dengan harap emosi sad. Penulis belum memastikan keakuratan dari deteksi emosi calm. Sedangkan emosi class neutral, belum dapat diklasifikasikan dengan baik, disebabkan sangat sulitnya arousal maupun valence, berada tepat nilainya di bagian tengah diagram.

\section{Saran}

Saran untuk pengembangan aplikasi lebih lanjut berdasarkan evaluasi dari user yang telah diperoleh :

- Saat ini jumlah class emosi yang dapat di deteksi sistem masih minimal, yaitu 5. Dan fitur yang dianalisa pun masih terbatas. Penelitian lebih lanjut untuk jumlah class emosi dan fitur maupun mengubahnya kedalam fuzzy dapat dipertimbangkan.

- Emotiv neuroheadset versi terbaru menyediakan fungsi dan elektroda yang lebih baik. Sehingga dapat meningkatkan keakurata sinyal yang diterima oleh sistem. Semakin banyak channel yang berfungsi maka akurasi dari sistem deteksi "EmoClass" ini akan meningkat.

- Pengenalan yang lebih spesifik terhadap emosi lainnya seperti (disgust, anxiety, joy) juga dapat ditambahkan pada sistem, sehingga sistem deteksi emosi dapat bekerja lebih menarik.

- Penambahan dataset dan menggabungkan hasil data kedalam multimodal dengan sinyal fisiologi lainnya, ekspresi muka, dan tatapan mata dapat diterapkan pada sistem, sehingga hasil akurasi dapat lebih tinggi lagi.

\section{DAFTAR PUSTAKA}

[1] Fabian Gieseke, Antti Airola, Tapio Pahikkala, and Oliver Kramer(2015) "Sparse QuasiNewton Optimization for SemiSupervised Support Vector Machines". In Proceedings of the 1st International Conference on Pattern Recognition Applications and Methods. pp 45-54.

[2] . Fausett, L R. E. (2018). An Introduction to Artificial Intelligence: Can Computers Think?, Boyd \& Fraser Publishing Company, San Francisco.

[3] Karl Pearson (2015) "Notes on regression and inheritance in the case of two parents, " Proceedings of the Royal Society of London, 58 : 240-242. Denmark

[4] M. Soleymani, J. Lichtenauer, T. Pun and M. Pantic (2011), "A MultiModal Affective Database for Affect Recognition and Implicit Tagging", IEEE Transactions on Affective Computing, Special Issue: Naturalistic Affect Resources, 
[5] R. Adolphs, D. Tranel, and A.R. Damasio,(2013) "Dissociable Neural Systems for Recognizing Emotions," Brain and Cognition, vol. 52,no. 1, pp. 61-69

[6] Royce, Winston W. (2016) "Managing the development of large software systems." proceedings of IEEE WESCON. Vol. 26. No. 8.
[7] S. Koelstra, C. Muhl, M. Soleymani, Jong-Seok, A. Yazdani, T. Ebrahimi, T. Pun, A. Nijholt and I. Patras (2014), "DEAP: A Database for Emotion Analysis using Physiological Signals," John wiley, USA 